\title{
Case Reporting in Homeopathy-An Overview of Guidelines and Scientific Tools
}

\author{
Michael Teut ${ }^{10}$ Robbert A. van Haselen ${ }^{2}$ Lex Rutten ${ }^{3}$ Chetna Deep Lamba ${ }^{4}$ Gerhard Bleul ${ }^{5, \dagger}$ \\ Susanne Ulbrich-Zürni ${ }^{6}$
}

${ }^{1}$ Institute for Social Medicine, Epidemiology and Health Economics, Charité Universitätsmedizin Berlin, corporate member of Freie Universität Berlin and Humboldt Universität zu Berlin, Luisenstr. 57, Berlin, Germany

2 International Institute for Integrated Medicine, Kingston, UK

${ }^{3}$ Independent Researcher, Breda, Netherlands

${ }^{4}$ Central Council for Research in Homoeopathy, Janak Puri, New Delhi, India

${ }^{5}$ Family Physician, Hünstetten, Kesselbach, Germany

${ }^{6}$ Institute of Integrative Medicine, Universität Witten-Herdecke,

Herdecke, Germany
Address for correspondence Michael Teut, MD, Institute for Socia Medicine, Epidemiology and Health Economics, Charité Universitätsmedizin Berlin, corporate member of Freie Universität Berlin and Humboldt Universität zu Berlin, Luisenstr. 57, Berlin, Germany (e-mail: michael.teut@charite.de).

Homeopathy 2022;111:2-9.

\begin{abstract}
Keywords

- homeopathy

- case reporting

- guidelines

- case research

Case reports have been of central importance to the development of homeopathy over the past 200 years. With a special focus on homeopathy, we give an overview on guidelines and tools that may help to improve the quality of case reports. Reporting guidelines such as CARE (Case Report), HOM-CASE (Homeopathic Clinical Case Reports), and the WissHom Documentation Standard help to improve the quality of reporting and strengthen the scientific value of a case report. Additional scientific tools such as prospective outcome assessment, prognostic factor research, cognition-based medicine, and the Modified Naranjo Criteria for Homeopathy (MONARCH) score may be helpful in improving case documentation and evaluation.
\end{abstract}

\section{Background}

Case reports have been of central importance for the development of homeopathy since it was founded more than 200 years ago. They document homeopathic clinical experiences and they explore homeopathic principles: e.g., they serve to corroborate proving symptoms and can extend the materia medica by adding symptoms based on clinical experience. As a didactic tool, they support homeopathic training and enable in-depth materia medica studies. Case reports can also be used as a scientific tool to help assess therapeutic effects, to

$\bar{\dagger}$ Dr. Gerhard Bleul died on June 3rd, 2020.

received

January 29, 2021

accepted after revision

April 12, 2021

published online

September 14, 2021
DOI https://doi.org/ 10.1055/s-0041-1731313. ISSN 1475-4916. generate hypotheses for research (e.g., observational studies and randomized controlled trials) and to identify or validate prescription criteria via the accumulation of high-quality case series. Moreover, case reports are also essential for evaluating the side effects of drugs (pharmacovigilance), the occurrence of homeopathic aggravations, and the appearance of old or proving symptoms during treatment.

Why are case reports still so attractive to clinicians in times of complex analytical statistical methods? Every case and every treatment is always, in a way, an "experiment" because it has never been done before with this individual patient. The clinician, researcher and epidemiologist Alvan Feinstein said, "In caring for patients, clinicians constantly (c) 2021. The Faculty of Homeopathy. All rights reserved.

This is an open access article published by Thieme under the terms of the Creative Commons Attribution-NonDerivative-NonCommercial-License permitting copying and reproduction so long as the original work is given appropriate credit. Contents may not be used for commercial purposes, or adapted, remixed, transformed or built upon. (https://creativecommons.org/ licenses/by-nc-nd/4.0/) Georg Thieme Verlag KG, Rüdigerstraße 14, 70469 Stuttgart, Germany 
perform experiments. During a single week of active practice, a busy clinician conducts more experiments than most of his laboratory colleagues do in a year". 1,2

The narrative aspect of case reports may also be important. Van Haselen ${ }^{3}$ reflects on the art of case reports: "So what is the secret behind the lasting appeal of Clinical Case Reports? One factor is that storytelling as a way of communication goes back to the moment we developed the ability to speak. We are therefore evolutionarily hardwired to listening to stories as a way of passing on information from generation to generation. Stories have added value to the community for thousands of years, so we should ask ourselves the question of what value case reports can add to medicine, particularly to complementary and alternative medicine ..."

A homeopathy case report, like any other clinical case report, should be very well and comprehensively documented. However, which information is most important and makes the most sense to include?

At present, there are a few international guidelines available on how medical case reports and homeopathy case reports can be optimally reported. Here, we present an overview of the CARE, HOM-CASE, and WissHom Guidelines that all aim to support the writing of a high-quality homeopathy case report.

Later in this article, we will also introduce the newest developments, tools and methods for assessing the likelihood of therapeutic causality in single cases.

\section{Guidelines}

\section{CARE}

The CARE guidelines (for Case Reports) were developed and published in 2013 by an international group of experts, including homeopathic and anthroposophic medicine doctors. The CARE guidelines are designed to increase the accuracy, transparency, and usefulness of all medical case reports and have been adopted by many international medical journals as a standard for case reporting. Homeopathic case reports should at least fulfil the CARE criteria. A CARE criteria checklist ( - Table $\mathbf{1}$ ) is available in various languages. The CARE guidelines are available online at the CARE Case Report guideline homepage, with open access via https:// www.care-statement.org/ The guidelines have been published in several journals. ${ }^{4,5}$

\section{HOM-CASE}

HOM-CASE stands for Homeopathic Clinical Case Reports. This guideline is a supplement/extension to the more general CARE guidelines, with additional focus on homeopathy needs. Using an online Delphi process, a panel of 19 homeopathic experts developed a criteria-catalogue serving as a guideline for authors to improve the quality of clinical case reports in homeopathy. This is the only case reporting guideline developed exclusively for homeopathy that has been published in an international peer-reviewed journal. Eight "core" items specific for homeopathy were selected: (1) the type of homeopathy; (2) the clinical history from a homeopathy perspective; (3) a detailed description of the medication; (4) manufacturer, (5) galenic form + dosage; (6) outcomes, objective evidence if available; (7) outcomes, occurrence of homeopathic aggravation; and (8) assessment of possible causal attribution of changes to the homeopathic treatment. We have added those criteria to the CARE guidelines in -Table 1. In addition, five "optional" items were identified for consideration, in particular when clinical case reports are used for educational or research purposes: (1) individualizing symptoms are reported; (2) repertorization data are provided; (3) disease evolution in accordance with homeopathic principles is reported; (4) the prescription strategy is made explicit; and (5) individual remedy-related symptoms are identified and analyzed. The guideline is available at the Complementary Therapies in Medicine journal website ${ }^{6}$ : https://www.sciencedirect.com/science/ article/pii/S0965229915300406?via\%3Dihub.

\section{WissHom Documentation Standard, Homeopathy}

This documentation standard was published by the German Scientific Society of Homeopathy (WissHom) and was developed in cooperation among three German homeopathy organizations between 2002 and 2008. The guideline includes seven areas: patient information, medical history, homeopathic interview, physical findings, case analysis, prescription, and follow-up monitoring; it includes 16 criteria for documenting case reports. This guideline is especially important for reporting and discussing cases in homeopathy journals as it relates more to practical and clinical homeopathy topics. The English and German versions are openly accessible at the WissHom website: https://www.wisshom.de/documentation-standard/ (last downloaded October 21, 2020). More information is also available from related publications of Gerhard Bleul. ${ }^{7-9}$

\section{Synthesis of Criteria}

- Table $\mathbf{1}$ is a synopsis of the criteria for scientific case reporting as laid out by the international CARE and HOMCASE guidelines. The WissHom documentation standard is not included.

\section{Scientific Tools and Methods}

In addition to high-quality case reports, researchers have developed several tools for homeopathic case research within the last two decades. Some of the tools, such as prospective outcome assessment, have been in use for a long time, whilst others, such as the Modified Naranjo Criteria score, are relatively new and require further research and validation.

\section{Prospective Outcome Assessment}

A method to improve the internal validity of case reports and also the quality of case reports from a quantitative perspective is to make use of prospective outcome assessment. "Prospective" means that in the first treatment session related to the clinical problem, the outcome assessments are defined, and then the patient is treated and observed over the follow-up. Identifying potential outcome measures that fit the patient and reflect the therapeutic aims at baseline 
4 Case Reporting in Homeopathy Teut et al.

Table 1 Summary of criteria for homeopathic case reporting in research

\begin{tabular}{|c|c|}
\hline CARE Guidelines Checklist, 2013 & $\begin{array}{l}\text { HOM-CASE } \\
\text { Supplement (core items) }\end{array}$ \\
\hline \multicolumn{2}{|l|}{ Title-The area of focus and "case report" should appear in the title. } \\
\hline \multicolumn{2}{|l|}{$\begin{array}{l}\text { Keywords-Two to five keywords that identify topics in this case } \\
\text { report. }\end{array}$} \\
\hline \multicolumn{2}{|l|}{$\begin{array}{l}\text { Abstract-(structured or unstructured) } \\
\text { Introduction-What is unique and why is it important? } \\
\text { The patient's main concerns and important clinical findings. } \\
\text { The main diagnoses, interventions, and outcomes. } \\
\text { Conclusion-What are one or more "take-away" lessons? }\end{array}$} \\
\hline \multicolumn{2}{|l|}{$\begin{array}{l}\text { Introduction-Briefly summarize why this case is unique, with } \\
\text { medical literature references. }\end{array}$} \\
\hline \multicolumn{2}{|l|}{$\begin{array}{l}\text { Patient Information } \\
\text { De-identified demographic and other patient information. } \\
\text { Main concerns and symptoms of the patient. } \\
\text { Medical, family, and psychosocial history, including genetic } \\
\text { information. } \\
\text { Relevant past interventions and their outcomes. }\end{array}$} \\
\hline $\begin{array}{l}\text { Clinical Findings-Relevant physical examination (PE) and other } \\
\text { clinical findings. }\end{array}$ & $\begin{array}{l}\text { Clinical history details (homeopathic symptoms used } \\
\text { for the decision, etc.). }\end{array}$ \\
\hline \multicolumn{2}{|l|}{$\begin{array}{l}\text { Timeline-Relevant data from this episode of care organized as a } \\
\text { timeline (figure or table). }\end{array}$} \\
\hline \multicolumn{2}{|l|}{$\begin{array}{l}\text { Diagnostic Assessment } \\
\text { Diagnostic methods (PE, laboratory testing, imaging, surveys). } \\
\text { Diagnostic challenges. } \\
\text { Diagnostic reasoning, including differential diagnosis. } \\
\text { Prognostic characteristics when applicable. }\end{array}$} \\
\hline $\begin{array}{l}\text { Therapeutic Intervention } \\
\text { Types of intervention (pharmacologic, surgical, preventive). } \\
\text { Administration of intervention (dosage, strength, duration). } \\
\text { Changes in the interventions, with explanations. }\end{array}$ & $\begin{array}{l}\text { Type of homeopathy: individualized/formula; single- or } \\
\text { multi-constituents/isopathy medication(s); } \\
\text { nomenclature (list individual prescriptions or } \\
\text { constituents + trade names), manufacture, potency, } \\
\text { scale, and galenic form. }\end{array}$ \\
\hline $\begin{array}{l}\text { Follow-up and Outcomes } \\
\text { Clinician and patient-assessed outcomes, when appropriate. } \\
\text { Important follow-up diagnostic and other test results. } \\
\text { Intervention adherence and tolerability (how was this assessed?) } \\
\text { Adverse and unanticipated events. }\end{array}$ & $\begin{array}{l}\text { Objective evidence (if applicable). (a) } \\
\text { Occurrence of homeopathic aggravation. (b) } \\
\text { Possible causal attribution of changes explicitly } \\
\text { assessed/discussed. (c) } \\
\text { (a) Objective evidence: Findings that reflect expert external } \\
\text { observation of any measurement of the patient. Objective } \\
\text { evidence includes laboratory tests, X-ray reports, health } \\
\text { care provider examinations or observations, or other } \\
\text { similar data (proposed by the HPUS Clinical Data Working } \\
\text { Group). } \\
\text { (b) Homeopathic aggravation: Criteria should be specified, } \\
\text { e.g., as defined in the glossary of the HPUS Clinical Data } \\
\text { guideline (https://www.hpus.com/HPCUS-Clinical-Data- } \\
\text { Guidelines-Draft-O8-2018.pdf): an expected, mild, } \\
\text { transient increase in pre-existing signs or symptoms that } \\
\text { occurs shortly after HMP administration, resolves quickly, } \\
\text { and is associated with improvements in clinical complaints } \\
\text { and/or general health. } \\
\text { (c) Causal attribution of changes: For assessment, } \\
\text { consider using the "Modified Naranjo Criteria" or the } \\
\text { updated MONARCH criteria. }\end{array}$ \\
\hline \multicolumn{2}{|l|}{$\begin{array}{l}\text { Discussion } \\
\text { Strengths and limitations in your approach to this case. } \\
\text { Discussion of the relevant medical literature. } \\
\text { The rationale for your conclusions. } \\
\text { The primary "take-away" lessons from this case report. }\end{array}$} \\
\hline \multicolumn{2}{|l|}{$\begin{array}{l}\text { Patient Perspective-The patient can share their perspective on } \\
\text { their case. }\end{array}$} \\
\hline Informed Consent-The patient should give informed consent. & \\
\hline
\end{tabular}

Abbreviations: HMP, homeopathic medicinal product; MONARCH, Modified Naranjo Criteria for Homeopathy. 
(first consultation) is essential. When choosing outcomes for scientific case reports, validated outcome measures may be considered for use. Conducting a literature review and choosing a common outcome measure for the clinical problem could be helpful. Examples are the "Conners Global Index" for ADHD, the "Hamilton Rating Scale for Depression", or the "Beck Depression Inventory". However, not all outcome measures are applicable or make sense for single-case research and for comparisons between baseline and the follow-up assessments. The ideal outcome measure should be easy to assess for the clinician and/or the patient and easy to evaluate (e.g., sum-scores, Likert scales). Using measures that assess general changes, which can be useful when comparing cases across different types of disease conditions, may also be considered. Examples of general outcome measures typically used for case research could be the intensity of symptoms on a numeric or visual rating scale, ${ }^{10}$ the Measure Yourself Medical Outcome Profile (MYMOP), ${ }^{11-13}$ and Outcome Related to Impact on Daily Living (ORIDL) (formerly known as the Glasgow Homeopathic Hospital Outcome Scale). ${ }^{14,15}$

Consideration might also be given to using Goal Attainment Scaling (GAS), ${ }^{16}$ which is an instrument used mainly in psychotherapy to check the achievement of individually defined therapeutic goals. It can be adapted to individualized homeopathic purposes. It first requires the definition of one or more therapeutic goals (outcomes). Indicators are then defined for each objective, and then the achievement of the objective can be checked. These indicators are converted into a five-step scale with the expected result in the middle. On this basis, usually two levels are formed upward ("more than expected" and "much more than expected") and two levels downward ("less than expected" and "much less than expected"). It is also possible to scale the GAS numerically, as a percentage or in words ("more achieved than the therapeutic goal; therapeutic goal achieved; therapeutic goal partially achieved; therapeutic goal not achieved").

The advantages of a prospective outcome assessment are better and more relevant feedback from the patient, improvement of the quality of the documentation, and an improvement in the quantitative assessment of the therapeutic outcome in case reports.

The disadvantages are that in many cases, especially in complicated and/or multi-morbid cases, clinicians may not have knowledge of an appropriate specific outcome measure at baseline. Moreover, these specific outcome measures can also be very comprehensive, and therefore their application can be time consuming and overwhelming for patients. Effort and benefit must therefore be carefully weighed. General outcome measures or individualized ones are much easier to apply. From a clinical perspective, prospective outcome assessment will lead to a deviation from routine clinical practice, and this could change, influence or disturb the "naturalistic" consultation process. When using prospective outcome measures, it may also be necessary to reflect whether the design has changed into an experimental study and if a research ethics committee's approval is therefore necessary. In this case the intervention has become experimental and is not a routine clinical intervention any more. Also, making use of an informed consent form for participation and an agreement for publishing anonymized or pseudonymized data may be necessary.

\section{Prognostic Factor Research and Bayes' Theorem}

According to the Simile principle, the prescription of homeopathic medicinal products (HMPs) in individualized homeopathy is based on the expectation that specific symptoms of the patient are accompanied by specific symptoms of an HMP and that a positive therapeutic course is predictable from this. This basic expectation has been answered in the 200year history of homeopathy from clinical experience, but not with mathematical concepts. Rutten et al developed an innovative mathematical model that uses Bayes' theorem and homeopathic symptoms as prognostic factors to establish the relationship between specific homeopathic symptoms and the effectiveness of a specific HMP. ${ }^{17}$ In this way, based on good case reports, homeopathic symptoms in materia medica and repertories can be systematically checked, confirmed, or rejected. This approach has recently been used, for example, to create a homeopathic repertory for the treatment of COVID-19 patients on the basis of casuistics. ${ }^{17}$ This is based on case collections, a promising research model for the future to improve the validity and prescription safety of homeopathic materia medica and repertories. This innovative approach has many methodological advantages but requires basic statistical and methodological knowledge and interest on the part of the practitioner.

\section{Prognostic Factors}

An essential prerequisite of homeopathy is that usually an HMP cannot be selected on the basis of the patient's main complaint/diagnosis alone; the HMP should also fit personal characteristics and symptoms. This insight is not exclusive to homeopathy or other complementary and alternative treatment modalities and is also accepted in personalized or stratified (conventional) medicine. ${ }^{18}$ Personal characteristics and symptoms can be regarded as prognostic factors influencing the outcome of the treatment, ${ }^{19}$ and this principle was recently illustrated in an individual patient data meta-analysis. ${ }^{20}$

In homeopathic case collection, the personal characteristics and symptoms of the patient are distinct from the biomedical condition/diagnosis and outcome measures with respect to the definition, standardization and validation. Homeopathic characteristics and symptoms typically represent the experience of an individual patient with a particular disease/diagnosis. Therefore, the variation due to semantics and confounders is considerably greater than the variation in the common characteristics and symptoms of patients with a particular disease/diagnosis. As an example of semantics in homeopathy, what is the difference between an "angry 
person" and an "irritable person"? The answer to this question may vary depending on age, gender, geographics, culture, and many others. A symptom such as "desire for sweets" is interpreted differently in southern India and in northern India regarding the cut-off for average sweets consumption. Homeopathic practitioners adjust the cut-off/threshold value for each symptom for each patient and their clinical judgment of confounders within the context of that therapeutic encounter. They estimate the intensity of symptoms in terms of "stronger than in most comparable people" or "stronger than in the average comparable person". As an example, a 4-year-old child stealing the left-overs in the coffee cups of visitors will be interpreted as "desire for coffee", but the daily consumption of five coffees by a salesman will be interpreted differently.

The interpretation of the intensity of symptoms is also influenced by the inclusion, confirmation or exclusion of HMPs deemed to be eligible for specific patients. As an example, the occurrence of herpes of the lips more than five times a year will be regarded as a reason to include the HMP Natrium muriaticum, whilst an occurrence of once in 2 years will only be regarded as a confirmation if the HMP is already indicated for other reasons. ${ }^{21}$ Exclusion of HMPs because a specific symptom is absent is relatively rare in homeopathy.

Homeopathic practitioners are not trained as observers in prognostic factor research. For an extensive discussion on this topic, see the book published by Rutten. ${ }^{22}$ Before participating in such research, they have to learn that they should handle the same threshold/cut-off values for inclusion (not confirmation) in case collection as in prescribing in daily practice. ${ }^{23}$ This involves clinical judgment, which may feel counterintuitive for many as part of a scientific assessment. This, however, is often the case in a prospective assessment of symptoms because, in that case, the symptoms are separated from their context. In daily practice, the threshold for "recurrent herpes of the lips" will be lowered to the confirmatory threshold if the context already indicates Natrium muriaticum, whilst it would introduce a lower threshold in prospective research. Therefore, on the one hand, the observer in prospective research has to use clinical judgment about the intensity of the symptom, but on the other hand, they should be aware that the presence of other symptoms may influence the threshold for any specific symptom.

The above-mentioned problem of varying thresholds can be resolved by allowing clinical judgment and using Likert scales. Such a Likert scale could contain items such as "Average", "Slightly more", "More", and "More than in most people". The "average" should be estimated by the homeopathic practitioner. Completion of the questionnaire should be guided by the practitioner explaining to the patient how the questionnaire can help reduce bias in the assessment of the patient's symptoms. Note that a Likert scale indicating the intensity of the complaint/symptom as experienced by the patient may need to be adjusted by the practitioner based on comparing the intensity of the complaint/symptom with a clinical judgment of the "average" in similar patients. The intensity of a symptom can be both underestimated and overestimated by the patient. Underestimation could occur if the patient has had symptoms for a long time and has become accustomed to them. Overestimation could be caused by willingness to please or by anxiety.

A further indication of the relevance or the intensity of a symptom is whether it is spontaneously reported by the patient or obtained based on questioning or questionnaires. Because spontaneously reported symptoms are potentially less affected by the problem of varying thresholds, it could be useful to "flag" symptoms obtained in this way.

Another criterion for including a symptom in the case description could be that the symptom appeared concomitantly with or after the onset of the illness.

In classical homeopathy, it is recommended that the practitioner deal carefully with "gut feelings" about possibly indicated HMPs until the final stages of the HMP selection process, when all or most of the symptoms have been collected and, ideally, the repertorization has been completed. Whilst this type of clinical judgment can be useful in the final stages of differentiating potentially indicated HMPs, during the earlier stages of the consultation, these types of "clinical intuition" as a "mental shortcut" (heuristic) may lead to confirmation bias. The latter is considered to be the most common bias affecting clinical decision making in medicine and is also referred to as "overconfidence" bias. ${ }^{24}$ For a more detailed discussion on biases and heuristics (shortcuts) in homeopathic decision making, see the article by Souter. ${ }^{25}$

\section{Quantitative Research and Bayes' Theorem}

When, say, the personal characteristic of "being an angry/irritable person" indicates a specific HMP, we intuitively interpret this as the characteristic being stronger than average in this person. This intuition can be translated into a mathematical formula using Bayes' theorem:

\section{Posterior odds $=\mathrm{LR} \times$ prior odds}

where $\mathrm{LR}=$ likelihood ratio= (prevalence in the medicine population)/(prevalence in the remainder of the population); odds $=$ chance $/(1-$ chance $)$, and chance $=$ odds $/(1+$ odds $)$

The "medicine population" is the population responding well to a specific medicine. Bayes' theorem indicates that if the prevalence of a characteristic/symptom in a specific medicine population is higher than in the remainder of the population (LR $>1$ ), the chance that the HMP will work increases, more so if the LR is higher. Since a population responding well to a specific HMP is only a small part of the whole population, LR $>1$ corresponds to "more than average".

Applying Bayes' theorem in homeopathy requires recording symptoms in the entire population and in sub-populations responding well to specific HMPs. This recording requires standardization of many symptoms, such as "anger" and all its semantic equivalents. 


\section{Assessment of Therapeutic Causality}

Therapeutic causality assessment means assessing the likelihood of a causal relationship between a therapeutic intervention and outcome. To assess causality in a case report is a very difficult task scientifically. In conventional medical science, case reports are often treated with ambivalence because their internal validity (as proof of the effectiveness of HMPs) is low. Case reports are an example of evidence that is frequently ignored because many people think that they cannot address causal links between a treatment and outcomes. Statistical analyses on efficacy or effectiveness mostly rely on repeated observations in a large number of patients, mostly in comparison with a group of untreated or differently treated patients.

However, there are some scientific tools available that may help to assess the likelihood of therapeutic causality in case reports.

\section{Modified Naranjo Criteria}

The Modified Naranjo Criteria for Homeopathy (Causal Attribution Inventory) tool was originally adapted by Rutten from the Naranjo algorithm, ${ }^{26}$ which was developed to assess therapeutic causalities for adverse drug reactions in single cases. This was further developed over several years by the Clinical Data Working Group of the Homoeopathic Pharmacopoeia Convention of the United States (HPCUS) to assess the likelihood of causal attribution of the clinical outcome to HMPs prescribed in homeopathic cases and case reports. The HOMCASE guideline refers to these criteria in the Modified Naranjo Criteria score for the assessment of causality. ${ }^{6}$ These criteria were further investigated and updated by Lamba et $\mathrm{al}^{27}{ }^{27}$ who referred to the Inventory under the acronym MONARCH, which stands for Modified Naranjo Criteria for Homeopathy.

Based on the assessment of 60 case reports of sufficient quality, except for items related to "direction of cure" (domains $6 \mathrm{~A}$ and $6 \mathrm{~B}$ ), the reliability and validity of all other domains of MONARCH were largely established. ${ }^{27}$

According to the final outcome in a case, which can also involve the sequential prescription of more than one HMP, a score is assigned to each domain of the MONARCH criteria. The higher the score, the more likely there is therapeutic causality. However, more research is needed on a potential threshold score of the MONARCH causality assessment. Also, exceptions may occur, depending on the nature of the disease, therapeutic goals, etc. Therefore, a low score does not rule out causal attribution to homeopathic treatment, but in such cases, justification of why the changes are considered to be due to the prescribed $\operatorname{HMP}(\mathrm{s})$ is even more important.

\section{Cognition-Based Medicine Assessment}

Another possibility for assessing therapeutic causality in single cases, which is even more demanding for the evaluator, is the assessment of a so-called "causal Gestalt process" in a case, also referred to as a cognition-based medicine (CBM) approach. This method was developed by Helmut Kiene and is based on Karl Duncker's Gestalt theory. ${ }^{28-31}$ It aims to assess therapeutic causalities at an individual level. The general idea is that doctors always judge the therapeutic effects of their intervention according to a set of cognitive criteria. Kiene identified cognitive patterns of causal relationship assessment in Duncker's Gestalt theory and adapted these to the assessment of therapeutic causalities in single patients. CBM adheres to the idea that cause and effect are generally connected by a socalled "Gestaltbezug", which is not arbitrarily related to time and space but potentially recognizable and understandable. The time and space of the cause are connected and interwoven with the time and space of the effect. When assessing the therapeutic causality of a case, the natural history of the disease, the success of previous treatments, and the fluctuations of disease symptoms before starting the reported treatment (baseline) must be considered.

More information on the CBM Gestalt approach can be obtained from Kiene, ${ }^{28}$ Kiene et al, ${ }^{31}$ and Teut. ${ }^{32}$

\section{Discussion}

Using case reporting guidelines and assessment tools helps to improve the quality of homeopathic case reports. Good case reports serve as an inspiration for the practitioner and clinical work, and can deepen the knowledge and skills of authors and readers on how to document cases in a better way and to question the role of the treatment. Applying a prospective outcome assessment in routine clinical work can further improve the internal validity and quality of a case report. The use of case reports in prognostic factor research is aimed at improving homeopathic clinical skills as well as enhancing the reliability of the materia medica and repertory rubrics. The MONARCH inventory can be used to assess the likelihood of therapeutic causality, but it is an innovation in homeopathy in need of further validation and elaboration.

Our review does not address single-case experimental study designs, such as single-case experiments, multiple baseline designs, and n-of- 1 randomized controlled trials. Readers interested in performing experimental research with single patients are referred to Teut, ${ }^{32}$ Guyatt, $^{33}$ Baker, $^{34}$ Teut \& Linde, ${ }^{35}$ Kravitz et al, ${ }^{36}$ and Ulbrich-Zürni et $\mathrm{al}^{37}$ for further information.

Since homeopathic practitioners play an essential role in homeopathy research, they should be trained from the start in reporting cases properly and in critical thinking as applied to case taking and decision making. This review illustrates that in recent years, a variety of guidelines and inventories have become available to improve the transparency and quality of clinical case reporting. Moreover, practitioners should be familiar with biases in decision-making, cut-off/ threshold values, and basic statistical notions such as variation, covariation, prevalence, and likelihood ratio. This will empower all practitioners to contribute meaningful, highquality data that are eligible for subsequent pooling and further interpretation.

Highlights

- We give an overview on case reporting guidelines and tools that can help to improve the scientific quality of homeopathy case reports. 
- Guidelines such as CARE, HOM-CASE, and the WissHom Documentation Standard help to improve the quality of reporting and strengthen the scientific value of a case report.

- Additional tools can be used for documentation (prospective outcome assessment) and evaluation (prognostic factors, Bayes' theorem, MONARCH, cognition-based medicine) to further improve the scientific quality of case reports.

\section{Funding}

This is a project of Wissenschaftliche Gesellschaft für Homöopathie (WissHom) and was funded by Homöopathie Stiftung des Deutschen Zentralvereins homöopathischer Ärzte and Robert Bosch Stiftung as part of the Homeopathic Guideline Project.

\section{Conflict of Interest}

None declared.

\section{Acknowledgements}

We thank Homöopathie-Stiftung des Deutschen Zentralvereins homöopathischer Ärzte, Robert-Bosch Stiftung, and Wissenschaftliche Gesellschaft für Homöopathie (WissHom), Germany, for supporting this project, the discussion process, and the publication of this manuscript. We thank all participants of the 2019 HRI Workshop in London on "Guidelines for designing and reporting homeopathic research" for reviewing and discussing an early draft of our manuscript.

We remember and thank our co-author Gerhard Bleul, who has died in 2020, for his lifelong contributions to homeopathy, especially in the field of case reporting. He was responsible for developing the WissHom Documentation Standard.

\section{References}

1 Feinstein AR. Clinical Judgment. Baltimore, MD: Williams \& Wilkins; 1967

2 Kienle GS. Why medical case reports? Glob Adv Health Med 2012; $1: 8-9$

3 van Haselen R. Harvesting the benefits of clinical case reports: how to separate the chaff from the wheat? Complement Ther Med 2015;23:139-140

4 Gagnier JJ, Kienle G, Altman DG, et al. The CARE guidelines: consensus-based clinical case reporting guideline development. Glob Adv Health Med 2013;2:38-43

5 Gagnier JJ, Kienle G, Altman DG, et al. The CARE guidelines: consensus-based clinical case report guideline development. J Clin Epidemiol 2014;67:46-51

6 van Haselen RA. Homeopathic clinical case reports: development of a supplement (HOM-CASE) to the CARE clinical case reporting guideline. Complement Ther Med 2016;25:78-85

7 Bleul G. Grundsätze und Elemente der FalldokumentationKonsensus aus Drei Konferenzen des DZVhÄ und InHom. Kongressdokumentation ICE 8. Köthen: InHom; 2009

8 Bleul G. Placeboeffekt oder arzneiwirkung-was zeigt die falldokumentation? Allg Homoopath Ztg 2015;260:21-25

9 Bleul G. Grundsätze der falldokumentation in der homöopathie. Allg Homoopath Ztg 2020;265:10-14
10 Witt CM, Lüdtke R, Baur R, Willich SN. Homeopathic medical practice: long-term results of a cohort study with 3981 patients. BMC Public Health 2005;5:115

11 Paterson C. Measuring outcomes in primary care: a patient generated measure, MYMOP, compared with the SF-36 health survey. BMJ 1996;312:1016-1020

12 Polus BI, Kimpton AJ, Walsh MJ. Use of the measure your medical outcome profile (MYMOP2) and W-BQ12 (Well-Being) outcomes measures to evaluate chiropractic treatment: an observational study. Chiropr Man Therap 2011;19:7

13 Thompson E, Viksveen P, Barron S. A patient reported outcome measure in homeopathic clinical practice for long-term conditions. Homeopathy 2016;105:309-317

14 Reilly D, Mercer SW, Bikker AP, Harrison T. Outcome related to impact on daily living: preliminary validation of the ORIDL instrument. BMC Health Serv Res 2007;7:139

15 Thompson EA, Mathie RT, Baitson ES, et al. Towards standard setting for patient-reported outcomes in the NHS homeopathic hospitals. Homeopathy 2008;97:114-121

16 Smith DL. Goal attainment scaling as an adjunct to counseling. J Couns Psychol 1976;23:22-27

17 Rutten L, Smedley T, Ives G, et al. Data collection during the COVID-19 pandemic: learning from experience, resulting in a Bayesian repertory. Homeopathy 2021;110:94-101

18 Hingorani AD, van der Windt DA, Riley RD, et al. Prognosis research strategy (PROGRESS) 4: stratified medicine research. BMJ 2013;346:e5793

19 Hemingway H, Croft P, Perel P, et al. Prognosis research strategy (PROGRESS) 1: a framework for researching clinical outcomes. BMJ 2013;346:e5595

20 van Haselen R. Development of a prognostic factor prediction model in patients with musculoskeletal pain treated with homeopathy: an individual patient data meta-analysis of three randomized clinical trials. Complement Med Res 2021;28:46-55

21 Rutten AL, Stolper CF, Lugten RF, Barthels RW. Statistical analysis of six repertory rubrics after prospective assessment applying Bayes' theorem. Homeopathy 2009;98:26-34

22 Rutten L. Prognostic Factor Research in Homeopathy. New Delhi: Central Council for Research in Homeopathy; 2019

23 Rutten L, Muraleedharan K, Shinde V, Manchanda R. What is a homoeopathic symptom, in daily practice and research? Indian J Res Homoeopathy 2017;11:12-20

24 Croskerry P, Norman G. Overconfidence in clinical decision making. Am J Med 2008;121:S24-S29

25 Souter K. Heuristics and bias in homeopathy. Homeopathy 2006; 95:237-244

26 Naranjo CA, Busto U, Sellers EM, et al. A method for estimating the probability of adverse drug reactions. Clin Pharmacol Ther 1981; 30:239-245

27 Lamba CD, Gupta VK, van Haselen R, et al. Evaluation of the modified Naranjo criteria for assessing causal attribution of clinical outcome to homeopathic intervention as presented in case reports. Homeopathy 2020;109:191-197

28 Kiene H. Komplementäre Methodenlehre der Klinischen Forschung Cognition-Based Medicine. Berlin, Heidelberg: Springer; 2001

29 Kienle GS, Hamre HJ, Portalupi E, Kiene H. Improving the quality of therapeutic reports of single cases and case series in oncologycriteria and checklist. Altern Ther Health Med 2004;10:68-72

30 Duncker K. Zur Psychologie des Produktiven Denkens. Berlin: Springer; 1935

31 Kiene H, Hamre HJ, Kienle GS. In support of clinical case reports: a system of causality assessment. Glob Adv Health Med 2013;2:64-75

32 Teut M. Scientific case studies in homoeopathy. Paper presented at: New Directions in Homeopathy Research-Advice from an Interdisciplinary Conference. Essen: KVC Verlag, 2009

33 Guyatt G, Sackett D, Adachi J, et al. A clinician's guide for conducting randomized trials in individual patients. CMAJ 1988;139:497-503 
34 Baker DS. A Research Model for the Scientific Investigation of Homoeopathy [dissertation]. Limsore, Australia: Australian Centre for Complementary Medicine Education and Research, University of Queensland and Southern Cross University, 2006

35 Teut M, Linde K. Scientific case research in complementary and alternative medicine-a review. Complement Ther Med 2013; 21:388-395
36 Kravitz RL, Duan N. Design and Implementation of N-of-1 Trials: A User's Guide. AHRQ Publication No. 13(14)-EHC122EF. Rockville, MD: Agency for Healthcare Research and Quality; 2014

37 Ulbrich-Zürni S, Teut M, Roll S, Mathie RT. The N-of-1 clinical trial: a timely research opportunity in homeopathy. Homeopathy 2018;107:10-18 